\title{
Low risk transcatheter aortic valve replacement: taking the plunge and embracing a paradigm shift
}

\author{
Anirudh Kumar ${ }^{1}$ (D), Michael J Reardon², Joseph A Lahorra1,3, Grant W Reed ${ }^{1}$, Samir \\ R Kapadia ${ }^{1}$ \& Ankur Kalra*,1,3 \\ ${ }^{1}$ Heart \& Vascular Institute, Cleveland Clinic Foundation, Cleveland, OH 44195, USA \\ ${ }^{2}$ Department of Cardiovascular Surgery, The Methodist Hospital, Houston, TX 77030, USA \\ ${ }^{3}$ Heart \& Vascular Center, Cleveland Clinic Akron General, Akron, OH 44307, USA \\ *Author for correspondence: Tel.: +33 0344 7400; Fax: +33 0344 2015; kalraa@ccf.org
}

"Introduction of TAVR has revolutionized the care of these patients."

First draft submitted: 29 November 2019; Accepted for publication: 18 February 2020; Published online: 3 March 2020

The landscape of managing patients with severe aortic stenosis (AS) has remarkably changed with the development of transcatheter aortic valve replacement (TAVR). TAVR was initially validated in inoperable patients with severe AS demonstrating superiority in comparison with use of medical therapy [1,2]. Technological advances and procedural simplification led to expansion to those at high surgical risk and subsequently intermediate surgical risk [3-6]. Societal guidelines have supported the use of TAVR as standard of care in these patients (Table 1) [7,8].

Most recently, TAVR was studied in severe AS patients with low surgical risk using both the self-expanding supra-annular bioprosthesis (CoreValve, Evolut R, Evolut PRO; Medtronic) [10] and the balloon-expandable valve (SAPIEN 3; Edwards Lifesciences Corp., CA, USA) [9] in comparison with those undergoing surgical aortic valve replacement (SAVR). Both studies were multicenter, randomized and noninferiority clinical trials. The Evolut Surgical Replacement and Transcatheter Aortic Valve Implantation in Low Risk Patients trial randomized 1468 patients with a mean age of 74 years and found an estimated incidence of the primary end point, defined as a composite of all-cause mortality or disabling stroke at 24 months, in $5.3 \%$ of patients undergoing TAVR versus $6.7 \%$ of patients undergoing SAVR (posterior probability of noninferiority $>0.999$ ) [10]. In terms of safety, patients who underwent TAVR, as opposed to SAVR, had a lower incidence of disabling stroke, bleeding complications, acute kidney injury and atrial fibrillation and a higher incidence of moderate or severe aortic regurgitation and pacemaker implantation at 30 days. The placement of aortic transcatheter valves (PARTNER) 3 trial randomized 1,000 patients with a mean age of 73 years and found the incidence of the composite end point, defined as all-cause mortality, stroke, or rehospitalization, to be significantly lower at 12 months among patients who underwent TAVR in comparison to SAVR (8.5 vs $15.1 \%$; $<0.001$ for noninferiority; $\mathrm{p}=0.001$ for superiority) [9]. Moreover, those who underwent TAVR had a lower risk for new-onset atrial fibrillation, poor treatment outcome and shorter index hospitalization with no significant between-group differences in major vascular complications, new permanent pacemaker insertions, or moderate or severe paravalvular regurgitation compared with those who underwent SAVR. As a result of these trials, TAVR was approved for use in low risk patients with severe AS by both the Centers for Medicare and Medicaid and US FDA.

In the background of these landmark studies, the number of TAVR procedures performed in the USA has now surpassed the number of isolated SAVR [11]. With the addition of low risk severe AS patients to this pool, the volume of TAVR is expected to rapidly increase and likely surpass all aortic valve procedures of any type in 2020 [12]. To put this into perspective, Thourani et al., described almost 80\% of 141,905 SAVR patients between 2002 and 2010 to be of low surgical risk [13]. In the future, a large proportion of these patients may instead undergo TAVR.

Additionally, recent studies have suggested that the need for TAVR may significantly increase for reasons outside of expansion into territory of which SAVR was previously the gold standard, including an underdiagnosis of severe AS in the community, a rising burden of disease, and possible benefit in patients with moderate AS. D'Arcy et al., reported identification of new valvular heart disease in half of primary care participants aged $\geq 65$ years old when

Future 8 Medicine 


\begin{tabular}{|c|c|c|c|c|c|c|c|c|}
\hline \multirow[t]{2}{*}{ Risk category/device } & \multirow[t]{2}{*}{ Trial } & \multicolumn{2}{|c|}{ 30-day mortality } & \multicolumn{2}{|c|}{ 30-day stroke } & \multicolumn{2}{|c|}{ 1-year mortality } & \multirow[t]{2}{*}{ Ref. } \\
\hline & & TAVR & SAVR & TAVR & SAVR & TAVR & SAVR & \\
\hline \multicolumn{9}{|l|}{ Inoperable } \\
\hline Balloon-expandable & PARTNER 1B & 5.0 & $\mathrm{~N} / \mathrm{A}$ & 6.7 & $\mathrm{~N} / \mathrm{A}$ & 30.7 & $\mathrm{~N} / \mathrm{A}$ & [1] \\
\hline Self-expanding & CoreValve extreme risk & 8.4 & $\mathrm{~N} / \mathrm{A}$ & 4.0 & N/A & 24.3 & $\mathrm{~N} / \mathrm{A}$ & [2] \\
\hline \multicolumn{9}{|l|}{ High risk } \\
\hline Balloon-expandable & PARTNER 1A & 3.4 & 6.5 & 3.8 & 2.1 & 24.2 & 26.8 & [3] \\
\hline Self-expanding & CoreValve high risk & 3.3 & 4.5 & 4.9 & 6.2 & 14.2 & 19.1 & [4] \\
\hline \multicolumn{9}{|l|}{ Intermediate risk } \\
\hline Balloon-expandable & PARTNER 2A & 3.9 & 4.1 & 5.5 & 6.1 & 12.3 & 12.9 & [5] \\
\hline Self-expanding & SURTAVI & 2.2 & 1.7 & 3.4 & 5.6 & 6.7 & 6.8 & [6] \\
\hline \multicolumn{9}{|l|}{ Low risk } \\
\hline Balloon-expandable & PARTNER 3 & 0.4 & 1.1 & 0.6 & 2.4 & 1.0 & 2.8 & [9] \\
\hline Self-expanding & Evolut low risk & 0.5 & 1.3 & 3.4 & 3.4 & 2.4 & 3.0 & [10] \\
\hline
\end{tabular}

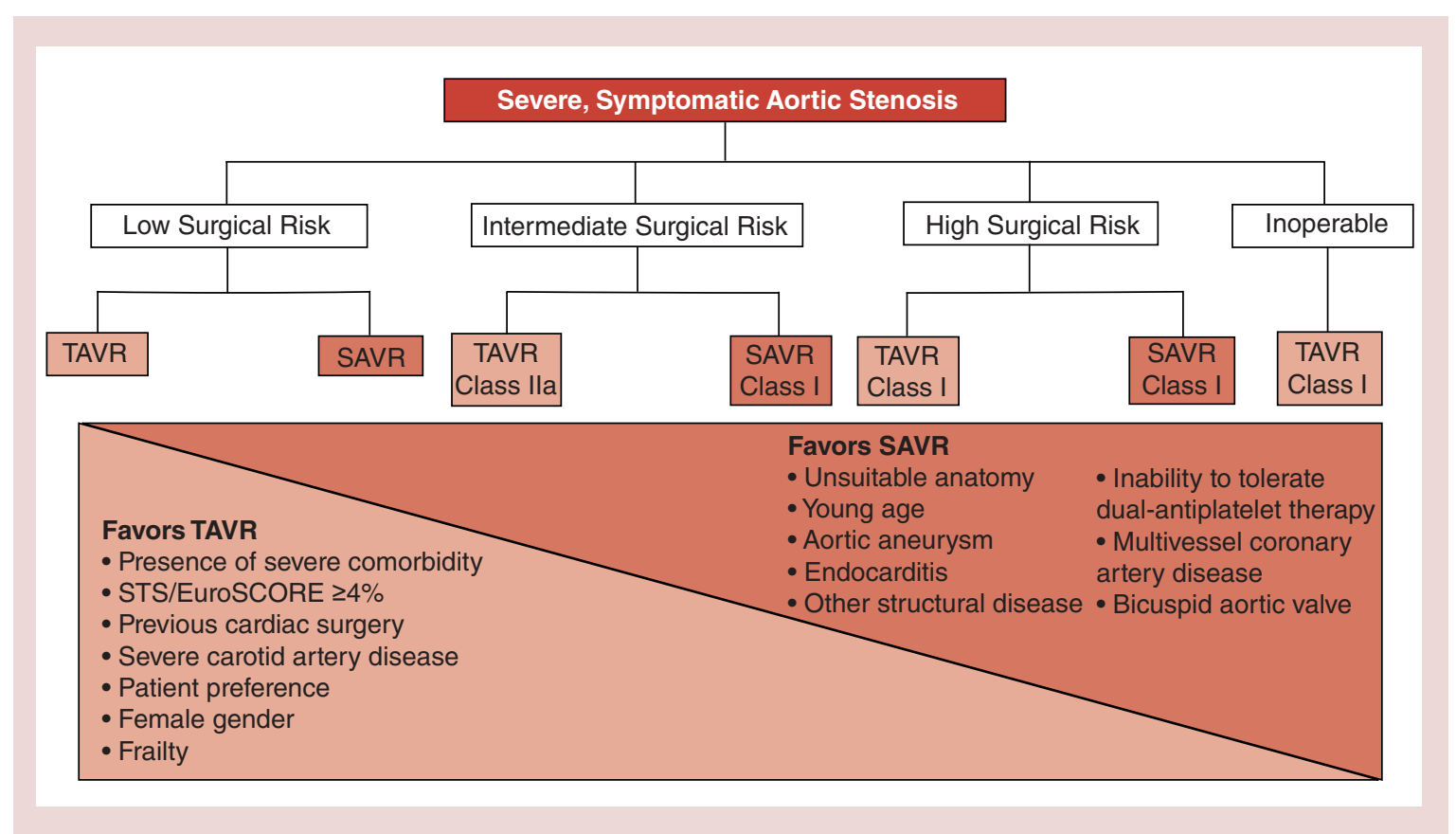

Figure 1. Factors influencing decision making for transcatheter aortic valve replacement versus surgical aortic valve replacement.

SAVR: Surgical aortic valve replacement; TAVR: Transcatheter aortic valve replacement.

screened with echocardiography in the OxVALVE Population Cohort study [14]. Extrapolating this to a population level, they estimated that clinically significant moderate-to-severe valvular heart disease would double by 2050 in the UK.

Moreover, the timing of aortic valve intervention among those with severe AS has become a controversial topic. While current guidelines support AVR as class I only when severe and symptomatic, there are data to suggest that these symptoms may be difficult to glean and can portend worse outcomes even if they are not reported [15]. Additionally, a recently published randomized controlled trial of 145 patients with very severe AS (mean aortic valve gradient $\geq 50 \mathrm{mmHg}$ ) demonstrated a lower mortality among patients treated with surgical AVR, supporting the premise that early intervention may benefit patients regardless of symptoms [16]. Furthermore, large datasets have also suggested that outcomes are worse among those with moderate AS $[17,18]$. These findings have built 
enthusiasm for the Evaluation of Transcatheter Aortic Valve Replacement Compared to SurveilLance for Patients with AsYmptomatic Severe AS (EARLY TAVR) trial. Positive findings from this study may further significantly increase TAVR volumes.

Going forward, where does this leave us? When making a personalized treatment strategy for a patient, it is prudent to consider the limitations of the aforementioned studies investigating TAVR (Figure 1). The most important limitation of these studies is lack of long-term follow-up investigating structural valve deterioration which remains the biggest deterrent for TAVR referral, particularly among younger patients $[19,20]$. Incidence and impact of late reduced leaflet motion, subclinical leaflet thrombosis, hypo-attenuating leaflet thickening and delineation of the optimal antiplatelet or anticoagulation regimens require further study. Both intermediate and low risk AS studies will follow clinical and echocardiographic outcomes over 10 years, with these findings being highly anticipated. Regardless, SAVR will remain highly relevant for patient subsets excluded from the low risk trials, namely those with poor transfemoral access, bicuspid aortic valve morphology, severe coronary or multivalve disease, and those with endocarditis and aortic aneurysms. Additionally, further study of valve-in-valve intervention needs to be performed among those who have previously undergone AVR.

In conclusion, the burden of AS continues to rise as we gain a greater understanding of its clinical impact. Introduction of TAVR has revolutionized the care of these patients. While recent trials demonstrating the safety of TAVR in the low risk AS population have greatly expanded its reach, they have raised important questions as well. Importantly, focus has shifted away from surgical risk to assessment of patient anatomy and valve morphology. Most importantly, though short- and intermediate-term results from NOTION [21], Evolut [2,4,6], and PARTNER [1,3,5] trials suggest similar hemodynamics and rates of structural valve degeneration as SAVR, the long-term durability of TAVR remains to be demonstrated. Looking ahead, proper patient selection utilizing a well-functioning heart team approach and informed patient preference remains of paramount importance.

\section{Financial \& competing interests disclosure}

The authors have no relevant affiliations or financial involvement with any organization or entity with a financial interest in or financial conflict with the subject matter or materials discussed in the manuscript. This includes employment, consultancies, honoraria, stock ownership or options, expert testimony, grants or patents received or pending, or royalties.

No writing assistance was utilized in the production of this manuscript.

\section{References}

1. Leon MB, Smith CR, Mack M et al. Transcatheter aortic-valve implantation for aortic stenosis in patients who cannot undergo surgery. N. Engl. J. Med. 363(17), 1597-1607 (2010).

2. Popma JJ, Adams DH, Reardon MJ et al. Transcatheter aortic valve replacement using a self-expanding bioprosthesis in patients with severe aortic stenosis at extreme risk for surgery. J. Am. Coll. Cardiol. 63(19), 1972-1981 (2014).

3. Smith CR, Leon MB, Mack MJ et al. Transcatheter versus surgical aortic-valve replacement in high-risk patients. N. Engl. J. Med. 364(23), 2187-2198 (2011).

4. Adams DH, Popma JJ, Reardon MJ et al. Transcatheter aortic-valve replacement with a self-expanding prosthesis. N. Engl. J. Med. 370(19), 1790-1798 (2014).

5. Leon MB, Smith CR, Mack MJ et al. Transcatheter or surgical aortic-valve replacement in intermediate-risk patients. N. Engl. J. Med. 374(17), 1609-1620 (2016).

6. Reardon MJ, Van Mieghem NM, Popma JJ et al. Surgical or transcatheter aortic-valve replacement in intermediate-risk patients. $N$. Engl. J. Med. 376(14), 1321-1331 (2017).

7. Nishimura RA, Otto CM, Bonow RO et al. 2017 AHA/ACC focused update of the 2014 AHA/ACC guideline for the management of patients with valvular heart disease: a report of the American College of Cardiology/American Heart Association Task Force on Clinical Practice Guidelines. Circulation 135(25), e1159-e1195 (2017).

8. Baumgartner H, Falk V, Bax JJ et al. 2017 ESC/EACTS guidelines for the management of valvular heart disease. Eur. Heart J. 38(36), 2739-2791 (2017).

9. Mack MJ, Leon MB, Thourani VH et al. Transcatheter aortic-valve replacement with a balloon-expandable valve in low-risk patients. $N$. Engl. J. Med. 380(18), 1695-1705 (2019).

10. Popma JJ, Deeb MH, Yakubov SJ et al. Transcatheter aortic-valve replacement with a self-expanding valve in low-risk patients. $N$. Engl. J. Med. 380(18), 1706-1715 (2019).

11. D'Agostino RS, Jacobs JP, Badhwar V et al. The Society of Thoracic Surgeons Adult Cardiac Surgery Database: 2019 update on outcomes and quality. Ann. Thorac. Surg. 107(1), 24-32 (2019). 
12. Bavaria JE. STS/ACC TVT Registry: Real world outcomes for TAVI. Presented at the $33^{\text {rd }}$ EACTS annual meeting, trial update and evidence review focus session Lisbon, Portugal (2019).

13. Thourani VH, Suri RM, Gunter RL et al. Contemporary real-world outcomes of surgical aortic valve replacement in 141,905 low-risk, intermediate-risk, and high-risk patients. Ann. Thorac. Surg. 99(1), 55-61 (2015).

14. d'Arcy JL, Coffey S, Loudon MA et al. Large-scale community echocardiographic screening reveals a major burden of undiagnosed valvular heart disease in older people: the OxVALVE Population Cohort Study. Eur. Heart J. 37(47), 3515-3522 (2016).

15. Zilberszac R, Gabriel H, Schemper M, Laufer G, Maurer G, Rosenhek R. Asymptomatic severe aortic stenosis in the elderly. JACC Cardiovasc. Imaging 10(1), 43-50 (2017).

16. Kang DH, Park SJ, Lee SA et al. Early surgery or conservative care for asymptomatic aortic stenosis. N. Engl. J. Med. 382(2), 111-119 (2020).

17. Strange G, Stewart S, Celermajer D et al. Poor long-term survival in patients with moderate aortic stenosis. J. Am. Coll. Cardiol. 74(15), 1851-1863 (2019).

18. Tastet L, Tribouilloy C, Marechaux S et al. Staging cardiac damage in patients with asymptomatic aortic valve stenosis. J. Am. Coll. Cardiol. 74(4), 550-563 (2019).

19. Dvir D, Bourguignon T, Otto CM et al. Standardized definition of structural valve degeneration for surgical and transcatheter bioprosthetic aortic valves. Circulation 137(4), 388-399 (2018).

20. Capodanno D, Petronio AS, Prendergast B et al. Standardized definitions of structural deterioration and valve failure in assessing long-term durability of transcatheter and surgical aortic bioprosthetic valves: a consensus statement from the European Association of Percutaneous Cardiovascular Interventions (EAPCI) endorsed by the European Society of Cardiology (ESC) and the European Association for Cardio-Thoracic Surgery (EACTS). Eur. Heart J. 38(45), 3382-3390 (2017).

21. Thyregod HGH, Ihlemann N, Jorgensen TH et al. Five-year clinical and echocardiographic outcomes from the Nordic Aortic Valve Intervention (NOTION) randomized clinical trial in lower surgical risk patients. Circulation 139(4), 2714- 2723 (2019). 